\title{
Research and book reviews
}

\section{Manual OF ASThMa management}

Edited by P. O'Bryne \& N. C. Thomson. W. B. Saunders, 1995. Price £29.95.

I $t$ is quite unusual these days to find a large (800 pages), comprehensive textbook for the relatively inexpensive price of $£ 30$. This paperback text is written by a selection of some of the most respected asthma experts in the world, a high proportion being from the UK. The book is divided into sections relating to the diagnosis and investigation of asthma, its treatment and management, and concludes with how to run an asthma service in both primary and secondary care. Overall, it is clearly written, wellpresented and up-to-date apart from a few omissions on recent developments in infant asthma/wheezing. References are copious, including articles up to 1994, and the most important areas are highlighted for ease of access. A major plus is a short summary of the most important points at the end of each chapter.

The book is aimed at specialists in respiratory medicine, paediatrics and general practice. Is it useful for the average GP? Probably not. However, if you have an interest in asthma it provides a good source of information reviewing all areas of asthma comprehensively and providing key references to further explore the literature if you need to. I found the chapters on allergen avoidance, devices, corticosteroids, patient education, self-management plans, compliance and chronic childhood asthma particularly well written and valuable to GPs. A chapter by Mark Levy succinctly reviews developments and research in primary care.

The book can be recommended as a reference work, but more importantly for GPs and nurses with an interest in asthma, to read and enhance their knowledge of this important disorder.

David Bellamy

A NATIONAL CENSUS FOR THOSE ATTENDING UK ACCIDENT AND EMERGENCY DEPARTMENTS WITH ASTHMA

Partridge M R, Latouche D, Trako E et al, on behalf of the UK National Asthma Task Force. $J$ of Accident and Emergency Medicine 1997; 14(1): 16-20.

$\mathrm{H}$

ow many of your patients attend $A \& E$ and what happens to them? This well written paper by Martyn Partridge and colleagues from the UK National Asthma Task Force surveyed 1292 patient attendances at 111 A\&E departments in one week in September 1994. A large proportion of adult attendees had non-acute problems, many presentations were repeat attendances and $61.6 \%$ of attenders aged under five were admitted. 'Asthma attack' was not defined. nor was severity classified, but the paper has interesting implications.

Better liaison and follow-up arrangements are needed between A\&E and practices, the availability of emergency dispensing of inhalers, by pharmacists, could be highlighted, and a perceived 'unavailability' of GPs needs to be addressed. The paper gives a balanced view of a complex problem. The 'take home' message is that primary care management of asthma is the responsibility of primary care.

Ron Neville

META-ANALYSIS OF RESPIRATORY REHABILITATION IN CHRONIC OBSTRUCTIVE PULMONARY DISEASE

Lacasse Y, Wong G, Guyatt G H et al. Lancet 1996; 348: 115-9.

$\mathrm{C}$ hronic obstructive pulmonary disease (COPD) is an increasingly important cause of mortality and morbidity. Lacasse and colleagues carried out a meta-analysis* of 14 high quality randomised trials testing the effects of exercise programmes on functional capacity (assessed by measuring walking distance) and quality of life (by validated questionnaires).

Most trials were out-patient or home-based, lasting between six and 12 weeks with patients who had moderate to severe COPD. To check whether the benefits were useful the authors compared the improvements with the 'minimum clinically important difference' (MCID) - the smallest difference regarded as important by patients. The authors found that exercise training improved both quality of life and functional capacity (by 60 metres in a six minute walk test). However, the magnitude of improvement, as judged by width of confidence intervals, was greater than the MCID only for two of four quality of life measures (dyspnoea and control over illness).

This study shows that exercise rehabilitation programmes relieve dyspnoea and improve control in patients with moderate to severe COPD. Furthermore these improvements are important to patients and are greater than those induced by bronchodilators or oral theophyllines. Whilst this makes exercise training a useful treatment several questions remain: for how long does the benefit persist after treatment ends; how cost effective are these programmes compared with, for example, drug treatment; and do the severest (e.g. housebound) COPD patients benefit?

* Meta-analysis is a technique that combines the results of systematically identified studies addressing a defined question to produce an overview describing an effect size with confidence intervals. 